\title{
Histiocitose de células de Langerhans: doença de Letterer-Siwe - importância do diagnóstico dermatológico em dois casos
}

\author{
Langerhans cell histiocytosis: Letterer-Siwe disease - the importance \\ of dermatological diagnosis in two cases
}

\author{
Leonardo Mello Ferreira ${ }^{1}$ \\ Lucia Martins Diniz ${ }^{3}$ \\ Isabella Redighieri ${ }^{5}$
}

\author{
Paulo Sergio Emerich ${ }^{2}$ \\ Luciene Lage $^{4}$
}

Resumo: A histiocitose de células de Langerhans é proliferação clonal de células fenotipicamente semelhantes às células de Langerhans. Anteriormente denominada Letterer-Siwe, é a forma mais comum e mais grave dessa enfermidade, acometendo sobretudo crianças até os dois anos de idade. São apresentados dois casos dessa rara doença, diagnosticados após parecer dermatológico, destacando-se seus aspectos mais característicos.

Palavras-chave: Células apresentadoras de antígenos; Etoposídeo; Imunoistoquímica; Microscopia eletrônica; Vimblastina

Abstract: Langerhans cell histiocytosis is defined as a clonal proliferation of Langerhans phenotypic-like cells. Letterer-Siwe disease is the most common and serious of these entities, affecting mainly infants up to two years of age. We present two cases of this rare disease, diagnosed after dermatological examination, highligthing its typical aspects.

Keywords: Antigen-presenting cells; Etoposide; Immunohistochemistry; Microscopy, electron; Vinblastine

\section{INTRODUÇÃO}

As histiocitoses são doenças proliferativas relacionadas ao histiócito, que é célula originada na medula óssea. ${ }^{1} \mathrm{O}$ termo histiócito envolve todos os tipos de macrófagos e demais células dendríticas (células apresentadoras de antígenos: dendrócitos dérmicos, células de Langerhans (CL) e células indeterminadas) ${ }^{2}$

Através da microscopia eletrônica e da imunohistoquímica (IHQ) as histiocitoses foram classificadas em: histiocitoses de células Langerhans (HCL), histiocitoses de células não Langerhans e as histiocitoses malignas. ${ }^{1,3}$

A LCH é proliferação clonal de células fenotipicamente semelhantes à $\mathrm{CL}$, que expressam imunofenóti- po positivo para CD1a e/ou contêm grânulos citoplasmáticos de Birbeck à microscopia eletrônica (ME), sendo seu formato em raquete patognomônico das CL. ${ }^{1,4}$ A presença de marcadores adicionais, como $\$ 100$, CD 207 (Langerina), CD68 e o fator XIIIa, pode auxiliar no diagnóstico diferencial com outras histiocitoses. ${ }^{4}$

A HCL é doença espectral, com quatro síndromes reconhecidas: doença de Letterer-Siwe (DLS) ou HCL aguda disseminada - presente até os dois anos; doença de Hand-Schüller-Christian ou HCL multifocal crônica - que aparece entre os dois e os seis anos; granuloma eosinofílico ou HCL focal crônica - frequente dos cinco aos 30 anos; e doença de HashimotoPritzker - variante autolimitada congênita. ${ }^{1,2,5}$

Recebido em 07.05.2007.

Aprovado pelo Conselho Consultivo e aceito para publicação em 23.10.08.

* Trabalho realizado na Escola de Medicina da Santa Casa de Misericórdia de Vitória (EMESCAM) e no Hospital Infantil Nossa Senhora da Glória (HISNG) - Vitória (ES), Brasil.

Conflito de interesse: Nenhum / Conflict of interest: None

Suporte financeiro: Nenhum / Financial funding: None

Pós-graduando do Serviço de Dermatologia da Escola de Medicina da Santa Casa de Misericórdia de Vitória (EMESCAM) - Vitória (ES), Brasil.

Especialista em dermatologia pela Sociedade Brasileira de Dermatologia. Preceptor de dermatologia da Residência em Pediatria do Hospital Infantil Nossa Senhora da Glória (HISNG) - Vitória (ES), Brasil.

Especialista em dermatologia pela Sociedade Brasileira de Dermatologia. Professora-assistente do Serviço de Residência em Dermatologia da Escola de Medicina da Santa Casa de Misericórdia de Vitória (EMESCAM) - Vitória (ES), Brasil.

Patologista do hospital da Santa Casa de Misericórdia de Vitória (EMESCAM) e do Hospital Infantil Nossa Senhora da Glória (HISNG) - Vitória (ES), Brasil.

Acadêmica do quinto ano de medicina da Escola de Medicina da Santa Casa de Misericórdia de Vitória (EMESCAM) - Vitória (ES), Brasil. 
A HCL desenvolve-se com mais frequência em crianças de um a três anos, apesar de poder ocorrer em qualquer idade. A incidência anual parece ser de dois a cinco casos por milhão de crianças. É duas vezes mais frequente no sexo masculino. ${ }^{1,3}$

A patogênese permanece desconhecida. Sua natureza reacional ou neoplásica ainda é debatida, embora existam mais argumentos a favor da primeira opção. ${ }^{3,4}$

Como doença espectral, os quadros clínicos das quatro bem definidas variantes da HCL podem sobrepor-se. ${ }^{1}$ Mais de $50 \%$ dos pacientes se apresentam inicialmente com manifestações cutâneas da doença, fato justificado, posto que, apesar de originárias da medula óssea, as CL pertencem fisiologicamente ao sitema imune da pele. ${ }^{4}$

A DLS ocorre mais frequentemente em menores de um ano. $\mathrm{O}$ acometimento cutâneo manifesta-se na maioria dos pacientes como pápulas róseas, amareladas ou da cor da pele normal, variando de um a dois milímetros, pústulas e/ou vesículas no couro cabeludo e áreas flexurais do pescoço, axila e períneo, e no tronco. As lesões tendem a coalescer e tornar-se mais firmes. Escamas, erosões, ulcerações e crostas, com infecção secundária, e o surgimento de petéquias e púrpuras são comuns. Em alguns casos ocorrem nódulos, que eventualmente ulceram. Pode acometer o nariz e a região palmoplantar. ${ }^{1,2}$

Durante o curso da doença, ocorrem febre e perda ponderal, ${ }^{2}$ e diversos órgãos podem ser infiltrados por clones de CL, pulmões, fígado, linfonodos e ossos, por exemplo. O sistema hematopoiético pode ser envolvido, ocorrendo trombocitopenia e anemia. ${ }^{1}$

O prognóstico é ruim. Em crianças com menos de dois anos de idade, com acometimento do sistema hematopoiético, fígado, pulmões e baço, apesar de tratamento agressivo, a mortalidade pode ser superior a $50 \% .{ }^{1,6}$

Na pápula típica, uma proliferação de CL está presente na derme papilar. Essas células são largas, com núcleo reniforme, e geralmente se verifica algum grau de infiltração epidérmica. $O$ infiltrado dérmico costuma incluir eosinófilos, neutrófilos, linfócitos, plasmócitos e mastócitos. Lesões antigas não proliferativas podem aparecer nas formas granulomatosa, xantomatosa ou fibrótica. ${ }^{1,7}$

O tratamento varia conforme a extensão e a gravidade do caso. ${ }^{1}$ Estudos recentes sugerem esquemas envolvendo vimblastina ou etoposídeo, associados à corticoterapia, em vez da multidrogaterapia aplicada anteriormente (DALHX 83-90), embora este último esquema apresente menor taxa de reativação da doença pós-tratamento. A falta de reposta terapêutica após seis semanas de tratamento é sinal de pior prognóstico e da necessidade de terapia com esquemas combinados mais agressivos. ${ }^{1,3,6}$

\section{RELATO DOS CASOS}

Caso 1: Paciente do sexo feminino, um ano e dois meses de idade, foi internada em centro de referência pediátrico, apresentando, há 30 dias, icterícia, colúria, acolia fecal, distensão abdominal, com massa palpável à esquerda, linfadenopatia inguinal e lesões cutâneas.

À ultrassonografia abdominal foi evidenciada hepatoesplenomegalia e iniciada antibioticoterapia empírica, sem alteração do quadro.

Foi então solicitado parecer dermatológico, observando-se lesões eritêmato-vésico-escamo-crostosas no couro cabeludo, região inguinal (Figura 1), pescoço e tronco, associadas a púrpuras, principalmente na região palmoplantar (Figura 2). Apresentava ainda algumas pápulas eritematosas no abdômen inferior e lesão nodular em couro cabeludo, que foi biopsiada. A hipótese diagnóstica foi de HCL, confirmada pelo exame histopatológico (Figura 3) e imuno-histoquímico (Figura 4). O mielograma não evidenciou acometimento medular da doença.

A conduta foi quimioterapia sistêmica com vimblastina associada a prednisona, com evolução favorável da doença. Outras internações, alguns meses depois, foram necessárias devido a complicações, sobretudo pulmonares. Posteriormente, perdeu-se o seguimento da paciente.

Caso 2: Paciente do sexo masculino, oito meses de idade, há dois meses iniciou edema de membros inferiores, febre esporádica e quadro semelhante ao de dermatite seborreica, evoluindo com otalgia, tosse seca, dispneia e icterícia. Houve piora progressiva, sendo então internado em serviço de referência pediátrico. Apresentava queda do estado geral, mucosas hipocoradas, anasarca, hipotensão, taquicardia, distensão abdo-

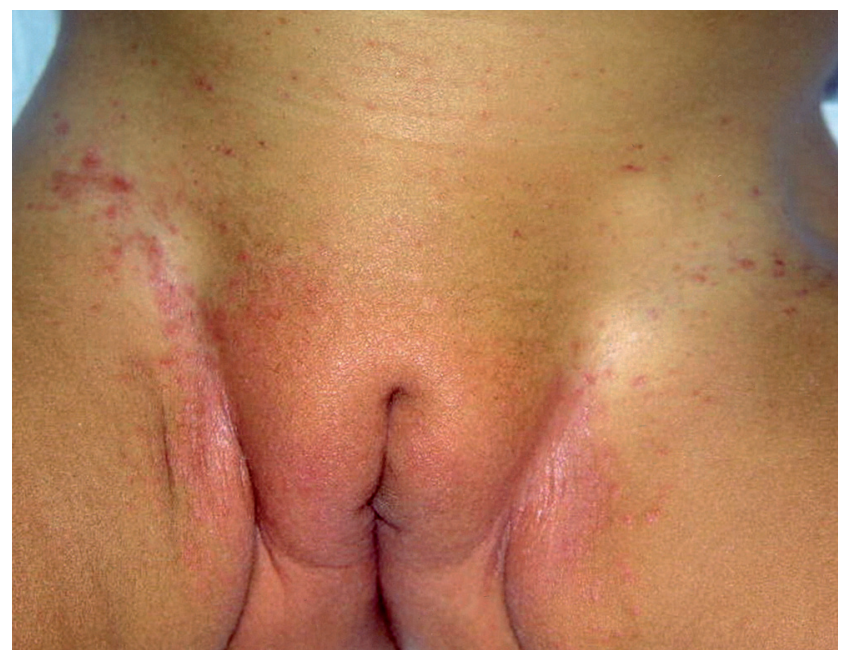

Figura 1: Caso 1: Lesões eritêmato-papulodescamativas na região ínguinocrural 


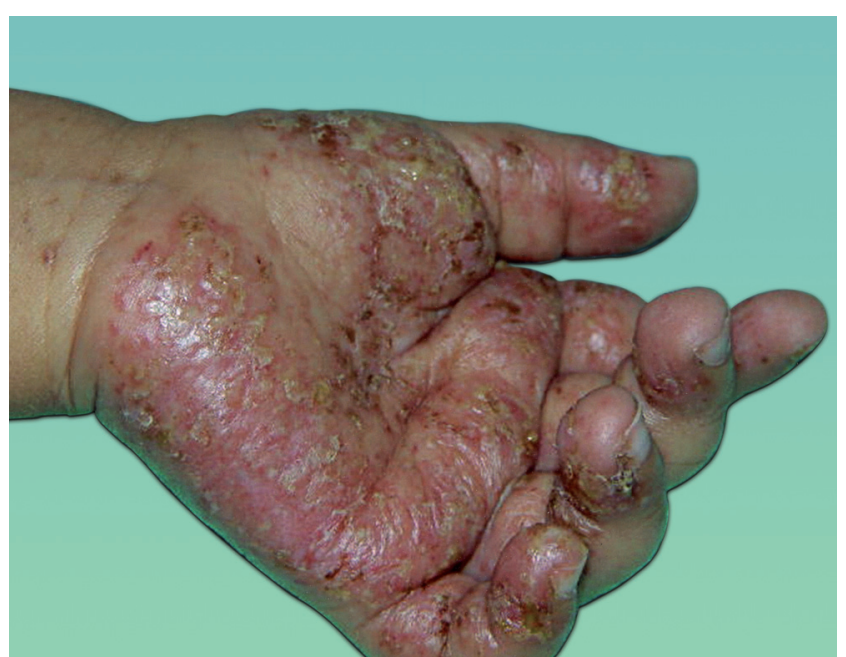

Figura 2: Caso 1: Aspecto característico: "eczema purpúrico"

minal, hepatomegalia, de difícil palpação, melena, circulação colateral visível, oligúria, colúria e lesões orais.

Os exames laboratoriais evidenciaram insuficiência hepática grave, anemia e trombocitopenia.

As hipóteses diagnósticas do serviço de pediatria incluíam sepse e desnutrição grave, hepatite fulminante, calazar, leucoses e várias outras afecções.

Sem resposta favorável à antibioticoterapia de amplo espectro, foi solicitado parecer dermatológico. O exame evidenciava anasarca, icterícia, petéquias generalizadas, telangiectasias, pequenas pápulas eritematosas no tronco, lesão ulceronecrótica na axila esquerda e quadro eritêmato-vésico-crostoso, descamativo e purpúrico, afetando couro cabeludo, extremidades de membros superiores (principalmente região palmar) e área das fraldas (Figura 5). Também, lesão

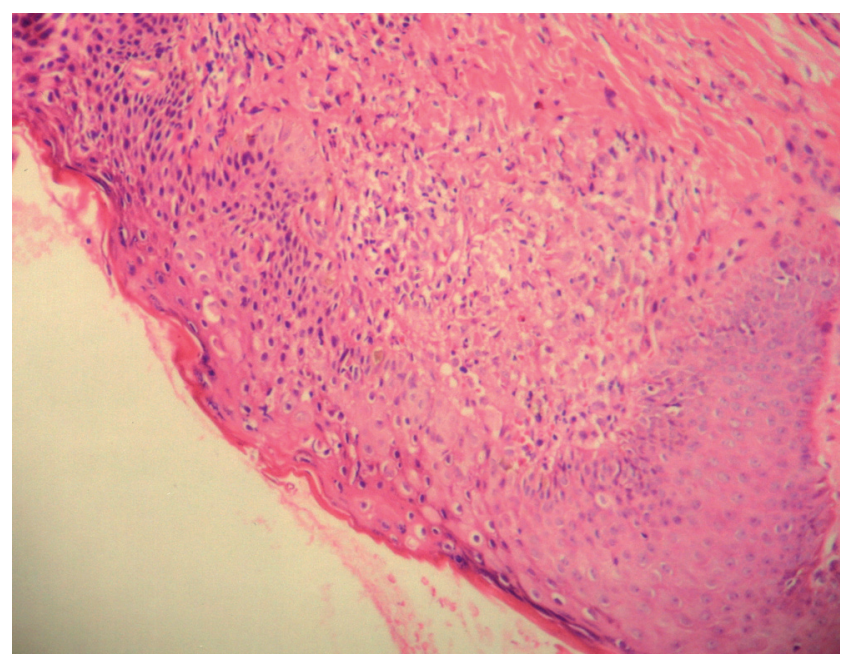

Figura 3: Caso 1: Exame histopatológico de nódulo de couro cabeludo: infiltrado histiocitário pleomórfico, em meio a eosinófilos e linfócitos na derme superior (HE, aumento de 20x)

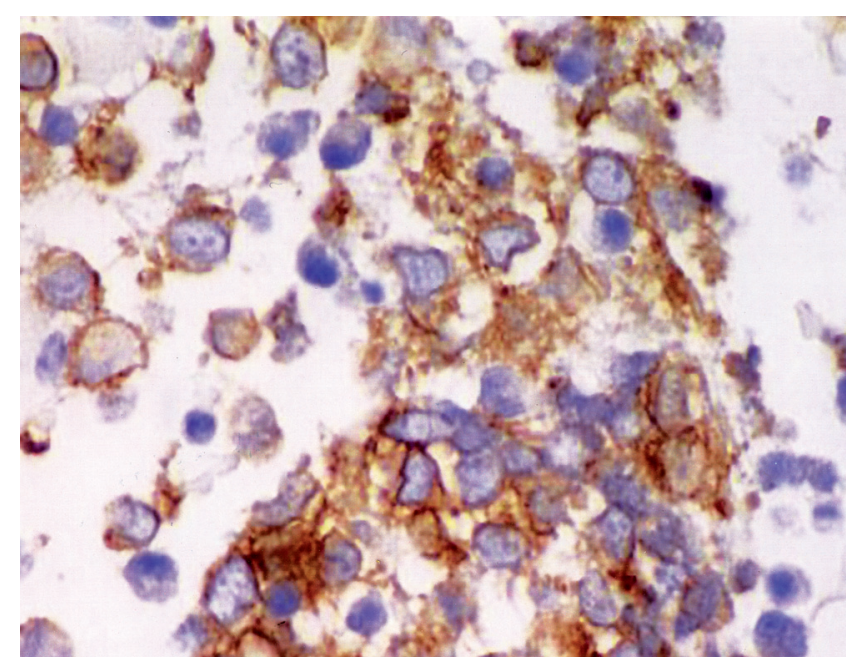

Figura 4: Caso 1: Imuno-histoquímica positiva para o antígeno CD1a, marcador mais específico

necrótica em palato e lesões púrpuro-hemorrágicas em cavidade oral. A hipótese diagnóstica foi de HCL.

O exame histopatológico da lesão de pele e o mielograma foram inconclusivos. O paciente evoluiu para óbito, por disfunção de múltiplos órgãos e sistemas.

A autópsia concluiu: HCL multissistêmica, acometendo pele (Figura 6), medula óssea, fígado, baço e pulmões, com posterior confirmação imuno-histoquímica.

\section{DISCUSSÃo}

A faixa etária, o quadro dermatológico, o exame histopatológico, o grau de envolvimento sistêmico e a progressão rápida da doença permitiram classificar esses dois casos como DLS.

O quadro dermatológico era típico em ambos, apresentando lesões que poderiam ser denominadas

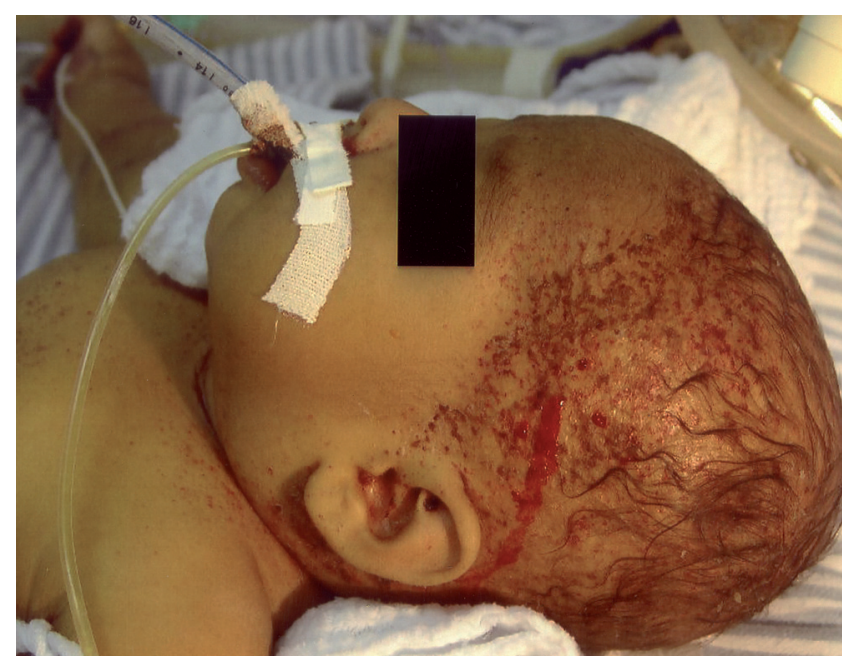

Figura 5: Caso 2: Quadro grave: Notar a icterícia e as lesões purpúricas e crostosas no couro cabeludo e tórax 


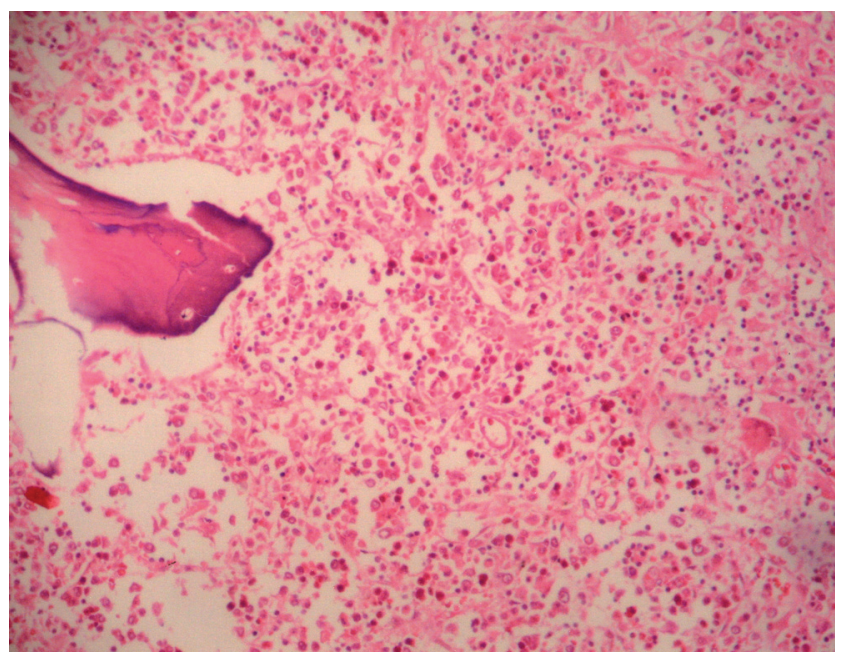

Figura 6: Caso 2: Exame histopatológico de pele apresentando infiltrado denso de histiócitos com citoplasma amplo e claro, núcleos com nucléolos evidentes, alguns com fendas, na derme superior (HE, aumento de 40x)

eczema purpúrico. Outros elementos estavam presentes, como a erupção de pápulas eritematosas acometendo o tronco, no segundo caso, e o nódulo de couro cabeludo, no primeiro.

Características secundárias, como crostas, pústulas, hemorragia e necrose, podem obscurecer o infiltrado característico da HCL, ${ }^{1}$ como se observou no exame histopatológico da biópsia de pele do segundo caso.

Com o auxílio da IHQ, a ME é cada vez menos necessária para o diagnóstico definitivo, ${ }^{1}$ como nesses dois casos: os antígenos CD1A, CD68 e proteína $\$ 100$ foram positivos.

O grau de acometimento hepático, no segundo paciente, justificou o extenso acometimento hemorrágico e o edema. Verificaram-se também, sinais de infiltração medular, como anemia e trombocitopenia (fator contribuinte para a hemorragia).

Lesões osteolíticas do processo mastóideo do osso temporal resultam em quadro de otite média, ${ }^{8}$ fato observado nos dois casos, precocemente, demonstrando tratar-se de característica importante para o diagnóstico da doença.

O primeiro paciente respondeu ao tratamento com vimblastina e prednisona, embora outras internações posteriores tenham sugerido reativações do quadro, o que é mais frequente com esquemas menos agressivos. Esquemas associando a vimblastina e o etoposídeo com ou sem outras medicações são promissores. ${ }^{6}$

$\mathrm{O}$ segundo paciente preenchia vários critérios de mau prognóstico, mas, é provável que o principal fator que o levou ao óbito precoce tenha sido o atraso no diagnóstico.

Resposta anômala a estímulos virais (HHV6, CMV, Epstein Barr, HIV), disfunções imunológicas dos linfócitos $\mathrm{T}$ e de citocinas ou anormalidades próprias das CL são hipóteses estudadas sobre a patogênese dessa doença. ${ }^{1,9}$

Pode-se exemplificar através de modelo hipotético envolvendo todos esses pontos. Considerando a existência documentada de casos familiares, ${ }^{1,3}$ indivíduos geneticamente predispostos teriam CL anormais (CLA). A estimulação da CLA por uma reação imune ou inflamatória levaria à expansão clonal de tal célula, assim como de células não clonais e potencialmente funcionais, originárias de CL normais. Essa população de CL induziria reação tecidual, resultando na lesão da HCL. O grau dessa lesão seria determinado pelo equilíbrio entre a agressividade das CL e a competência do sistema imune regulatório, justificando as diferentes formas e os cursos clínicos da $\mathrm{HCL}^{3}$

Os dois casos foram diagnosticados a partir de parecer dermatológico, apesar de propedêutica e hipóteses diagnósticas do serviço especializado.

Os autores concluíram que a DLS é afecção rara, mas, devido a sua gravidade, o dermatologista deve estar apto a reconhecer os característicos sinais dermatológicos da doença, o que pode ser decisivo na conduta e no prognóstico dos pacientes. 


\section{REFERÊNCIAS}

1. Goodman WT, Barret TL. Histiocytoses. In: Bolognia JL, Jorizzo JL, Rapini RP, editors. Dermatology . Philadelfia: Mosby; 2003.p.1429-33.

2. Vieira AG, Guedes LS, Azulay DR. Histiocitoses. In: Azulay RD, Azulay DR, editors. Dermatologia. 3 ed. Rio de Janeiro: Guanabara Koogan; 2004.p.355-6.

3. Savasan S. An enigmatic disease: childhood Langerhans cell histiocytosis in 2005. Int J Dermatol. 2006; 45:182-8.

4. Querings K, Starz H, Balda BR. Clinical spectrum of cutaneous Langerhans' cell histiocytosis mimicking various diseases. Acta Derm Venereol. 2006;86:39-43.

5. Schachner LA, Hansen RC. Pediatric Dermatology. 3 ed. Philadelphia: Mosby; 2003.p.893-6.

6. Gadner H, Grois N, Arico M, Broadbent V, Ceci A, Jakobson A, et al. A randomized trial of treatment for multisystem Langerhans' cell histiocytosis. J Pediatr. 2001;138:728-34.

7. Punia RS, Bagai M, Mohan H, Thami GP. Langerhans cell histiocytosis of skin: a clinicopathologic analysis of five cases. Indian J Dermatol Venereol Leprol. 2006;72:211-4.
8. Fabrini-Araújo PAF, Pimentel APS, Machado Pinto J, Bueno Neves L. Histiocitose de células de Langerhans O papel do sistema imunológico na sua etiopatogenia. An Bras Dermatol. 1999; 74:249-52.

9. Vizcaya M, Urdaneta LM, Ascanio A, Pérez N. Histiocitosis $\mathrm{X}$ o de células de Langerhans: a propósito de un caso. Rev Venez Oncol. 2005;17:103-6.

ENDEREÇO PARA CORRESPONDÊNCIA / MAILING ADDRESS: Leonardo Mello Ferreira.

Av. Governador Lindenberg 1066 / $3^{\circ}$ Andar Centro 29900202 Linhares ES

Tel./Fax: 2732641908

e-mail: leonardomellof@gmail.com

Como citar este artigo/How to cite this article: Ferreira LM, Emerick PS, Diniz LM, Lage L, Redighieri I. Histiocitose de células de Langerhans: doença de Letterer-Siwe -importância do diagnóstico dermatológico em dois casos. An Bras Dermatol. 2009;84(4):405-9. 